\title{
PILOT RCT: BOWEL FUNCTION: LOW-DOSE KETAMINE AFTER BOWEL SURGERY
}

William PS McKay MD and Phillip Donais MD, Dept of Anesthesia, University of Saskatchewan, RUH, 103 Hospital Drive, Saskatoon SK, S7N 0W8

INTRODUCTION Morphine patient-controlled intravenous analgesia (PCIA) is often used to provide pain control after bowel surgery. Unfortunately, the bowel wall opiate receptors decrease bowel peristalsis in the presence of morphine.

Ketamine, a non-opioid analgesic, is safe and efficacious in very low doses when combined with morphine for post-operative pain control [1,2]. Since the addition of ketamine to morphine PCIA results in lower use of morphine, and since ketamine does not slow peristalsis, low-dose ketamine plus PCIA morphine should result in faster return of bowel function than PCIA morphine alone.

METHODS A double-blind randomised controlled trial (RCT), with PCIA morphine (1mg with a 6-minute lockout) and a background infusion of either saline or ketamine at $2.5 \mathrm{mcg} / \mathrm{kg} / \mathrm{minute}$ was approved by the university Research Ethics Board and conducted in a tertiary-care teaching hospital, with 42 subjects having bowel surgery, using an intent-to-treat protocol. Bowel function was assessed twice-daily by: 1) stethoscope auscultation for bowel sounds for 30 seconds; 2) asking subjects if they had passed flatus, or 3) stool per rectum or per ostomy; 4) measurement of nasogastric (NG) suction volumes where NG tubes were in place; and 5) recording the time of first $120 \mathrm{ml}$ drink or of solid food which was retained. Resting pain control was assessed using a visual analogue scale, and side effects were recorded. PCIA morphine use was measured.

RESULTS Despite using an infusion dose previously shown to decrease morphine use, we found no difference in any measure of bowel function; no difference in pain control; and no difference in morphine use between the two groups. The dose of ketamine found to be free of side effects in previous studies resulted in hallucinations in 6 of 19 patients, with no hallucinations in the placebo group $(\mathrm{P}=0.006)$.

DISCUSSION A low-dose ketamine infusion at a dose found to be safe and efficacious in another study, run as a background to PCIA morphine, caused hallucinations, and did not improve pain control or hasten return of bowel function. These findings are unexpected.

REFERENCES [1] Pain 1999; 82: 111- 125. [2] Br J Anaesth 1999; 83(3): 393 -6. 